Int. J. Dev. Biol. 57: 707-714 (2013)

doi: $10.1387 / \mathrm{ijdb} .130204 \mathrm{mo}$

\title{
Unraveling new roles for serotonin receptor 2B in development: key findings from Xenopus
}

\author{
MICHELA ORI ${ }^{*, 1}$, STEFANIA DE LUCCHINI'², GIULIA MARRAS ${ }^{1}$ and IRMA NARDI ${ }^{1}$ \\ ${ }^{1}$ Unità di Biologia Cellulare e dello Sviluppo, Dipartimento di Biologia, Università di Pisa and \\ ${ }^{2}$ Scuola Normale Superiore di Pisa, Pisa, Italy
}

\begin{abstract}
The serotonin receptor 5-HT2B has been shown to be critically important during embryogenesis as the knockout of this gene in mice causes heart defects and embryonic lethality that impairs further analyses on other embryonic cell and tissue types. In the present review, we highlight how the use of Xenopus laevis, an alternative vertebrate model suitable for gene loss and gain of function analyses, has contributed to our understanding of the role of 5-HT2B signaling during development. In vivo studies showed that 5-HT2B signaling is not only required for heart development, but that it also has a crucial role in ocular and craniofacial morphogenesis, being involved in shaping the first branchial arch and the jaw joint, in retinogenesis and possibly in periocular mesenchyme development. These findings may be relevant for our understanding of congenital defects including human birth malformations. In addition, 5-HT2B appears to be required for the therapeutic actions of selective serotonin reuptake inhibitors commonly prescribed as antidepressant drugs to pregnant and lactating women. We discuss how the understanding of the molecular basis of serotonin signaling in a suitable animal embryogenesis model may open new lines of investigations and therapies in humans.
\end{abstract}

KEY WORDS: 5-HT2B, neural crest cell, eye, craniofacial morphogenesis, SSRI

Serotonin, an ancient molecule with unsuspected and still unveiled functions

Serotonin (5-hydroxytryptamine, 5-HT) is a phylogenetically ancient monoamine that fulfills a broad role in the control of many vital functions including the control of gastrointestinal motility and secretion, cardiovascular regulation, hemostatic processes, the regulation of circadian rhythms, the control of the sleep-wake cycle, memory and learning, perception of pain, appetite and sexual behavior (reviewed by Berger et al., 2009). The broad action of the serotonin signaling system has attracted the interest of researchers in various fields of biology and molecular medicine, spanning from developmental biology, neurobiology to molecular psychiatry.

$5-\mathrm{HT}$ is best known for its role in the nervous system where it is one of the neurotransmitters mainly involved in the etiology of various human psychiatric disorders, including anxiety, depression, obsessive-compulsive disorders, schizophrenia, pain and migraine. Accordingly, many substances that interfere with the serotonergic system are commonly used as therapeutic agents. Selective serotonin reuptake inhibitors (SSRIs) are, in fact, the most frequently prescribed drugs for the treatment of depression and anxiety-related disorders (Berton and Nestler, 2006). These drugs inhibit the function of the serotonin transporter (5-HTT) inducing an accumulation of extracellular 5-HT and an increase of the magnitude and duration of the activity of $5-\mathrm{HT}$ on $5-\mathrm{HT}$ receptors (Shafer et al., 1999).

In the adult brain 5-HT is synthesized in serotonergic neurons of the raphe nuclei that represent one of the most widely distributed neuronal systems in the vertebrate brain. In addition, several other tissues produce large amount of $5-\mathrm{HT}$, namely the pineal gland, where $5-\mathrm{HT}$ is a precursor of melatonin, the enterochromaffin and myenteric cells of the gut and the bone (cf. Tsapakis et al., 2012). Collectively, the tissue sources outside the brain produce about $95 \%$ of $5-\mathrm{HT}$.

Since the pioneer studies of Buznikov and his collaborators (reviewed in Buznikov, 2007) it has becoming clear that 5- HT,

\footnotetext{
Abbreviations used in this paper: 5-HT, serotonin; 5-HTT, serotonin transporter; CNS, central nervous system; CMZ, ciliary marginal zone; Edn1, endothelin 1; GCL, gaglion cell layer; INL, inner nuclear layer; NCCs, neural crest cells; POM, periocular mesenchyme; SSRI, selective serotonin reuptake inhibitors; Tph2, tryptophan hydroxylase 2.
}

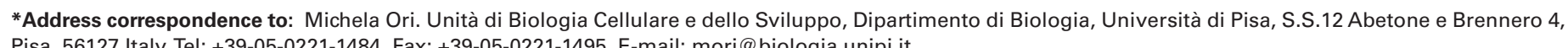
Pisa, 56127 Italy.Tel: +39-05-0221-1484. Fax: +39-05-0221-1495. E-mail: mori@ biologia.unipi.it 
in addition to its well defined function as neurotransmitter, participates in the regulation of early development in many animal phyla before the onset of neurogenesis. 5-HT thus plays a role as a morphogen-like signal in development before it acts as a neurotransmitter (Lauder, 1993; Gaspar et al., 2003). 5-HT synthesis and uptake become active at early stages during embryogenesis where it modulates a number of developmental processes including cell proliferation, migration and differentiation (Gaspar et al., 2003). During mammalian embryogenesis 5-HT is supplied to the embryo by the maternal blood (Côté et al., 2007). Moreover, an early transient placental source of $5-\mathrm{HT}$ for the fetal circulation has been detected both in mice and humans (Bonnin et al., 2011). In the central nervous system (CNS) serotonergic neurons are among the earliest neurons to be generated and 5-HT is released by growing axons before conventional synapses are established. In addition to the sites of 5-HT production, there are a number of cells that capture and store $5-\mathrm{HT}$, acting as 5- $\mathrm{HT}$ reservoirs during development. In mice uptake of 5-HT during early development is first observed in non-neural tissues such as the heart, the liver, the cranial mesenchyme, the migrating cranial neural crest cells (NCCs), dorsal ganglia and retinal ganglion cells (Lauder and Zimmerman, 1988; Narboux-Nème et al., 2008). High affinity uptake of $5-\mathrm{HT}$ in these structures highlights the involvement of 5-HT signaling in their development and suggests that 5-HT must be finely modulated.

So far evidence has been presented for 5-HT involvement in the establishment of left-right asymmetry, the craniofacial, limb, bone and heart development, the closure of the neural tube and neuronal differentiation during early neurogenesis (Whitaker-Azmitia, 2001; Levin et al., 2006; Beyer et al., 2012; Vandenberg et al., 2013). In mice 5-HT has been found to influence the development of the whisker-barrel fields in the somatosensory cortex and the thalamocortical axon guidance, suggesting that dysfunction of 5-HT signaling during development may alter brain circuitry and functioning (Cases et al., 1996; Persico et al., 2001; Bonnin et al., 2007). Recently, the generation of a knockout mouse line lacking the tryptophan hydroxylase 2 (Tph2), the brain enzyme for 5-HT synthesis, has shown that the lack of 5-HT in the brain produces severe abnormalities in the serotonergic circuitry (Migliarini et al., 2012).
The biological actions of $5-\mathrm{HT}$ are mediated by numerous cognate receptors that are grouped into seven classes (5-HT1-7). Except for 5-HT3 receptors, which are ligand-gated ion channels, all belong to $G$ protein-coupled receptors and among these, the 5 -HT2 receptors class seems to be particularly important in mediating the effects of 5-HT on embryonic development. Blockade of serotonergic signaling by the pan-5-HT2 receptor antagonist ritanserin perturbs development of the heart, the face and eyes both in mice and Xenopus, suggesting a conservation of this signaling pathway across vertebrate evolution (Choi et al., 1997; Bhasin et al., 2004; De Lucchini et al., 2005). The 5-HT2B receptor has been shown to be an important regulator of the mouse cardiac morphogenesis since its genetic ablation leads to mouse embryonic and postnatal lethality due to abnormal heart development (Nebigil et al., 2000; Nebigil et al., 2001). 5-HT2B knockout increases impulsive behaviors in mice and a human population-specific 5-HT2B stop codon was found to be associated with psychiatric diseases marked by impulsivity (Bevilacqua et al., 2010). 5-HT2B receptor is also present on embryonic raphe neurons and takes part in the control of 5-HTT functions in differentiating serotonergic cells (Launay et al., 2006). Recently, it has been shown to be required for the therapeutic actions of SSRIs (Diaz et al., 2012). These findings indicate that the $5-\mathrm{HT} 2 \mathrm{~B}$ receptor has important roles both in periphery and in the CNS and that it is one of the key mediators of 5-HT functions during development.

In this review we focus on the 5-HT2B receptor with the aim to show how the use of a suitable model system, Xenopus laevis, allowed to unveil new roles of this receptor thanks to the availability of sophisticated tools for manipulating embryos and gene functions. In particular, this review highlights how such studies provided detailed information about the mechanisms of 5-HT2B receptor function in two complex morphogenetic processes such as craniofacial and ocular development.

\section{Xenopus as a vertebrate model system for develop- mental studies}

Choosing a suitable animal model system to unveil new roles of the serotonin signaling during development is one of the most important steps for achieving meaningful results.
Antisense Morpholino Gene Loss Of Function Strategy

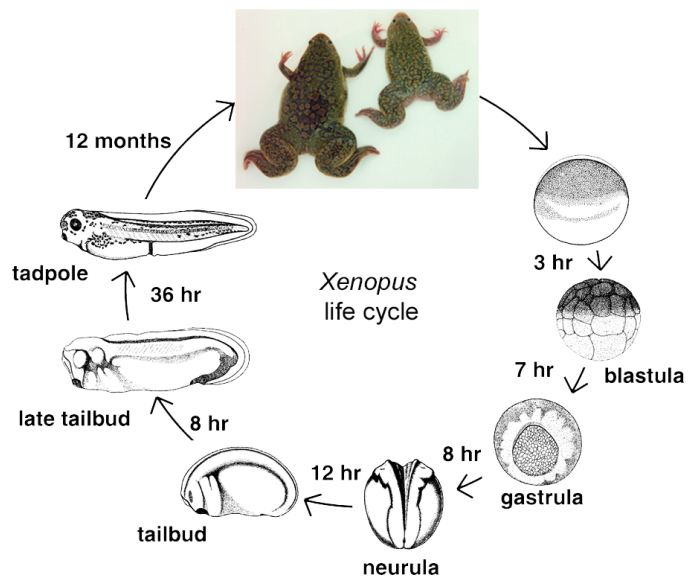

Fig. 1. Xenopus laevis as a model system to study gene function. On the left, the life cycle of Xenopus laevis. On the right, the gene loss of function strategy that specifically blocks the translation of a gene of interest by microinjecting specific morpholino oligos in one side of the embryo. Antisense morpholino is targeted to sequences close to the translation start site. The injected side is visualized by the co-injection of a reporter mRNA such as LacZ or GFP. Examples of chromogenic reaction for beta galactosidase (red) and GFP (green fluorescence) are shown in neural stage embryos. 

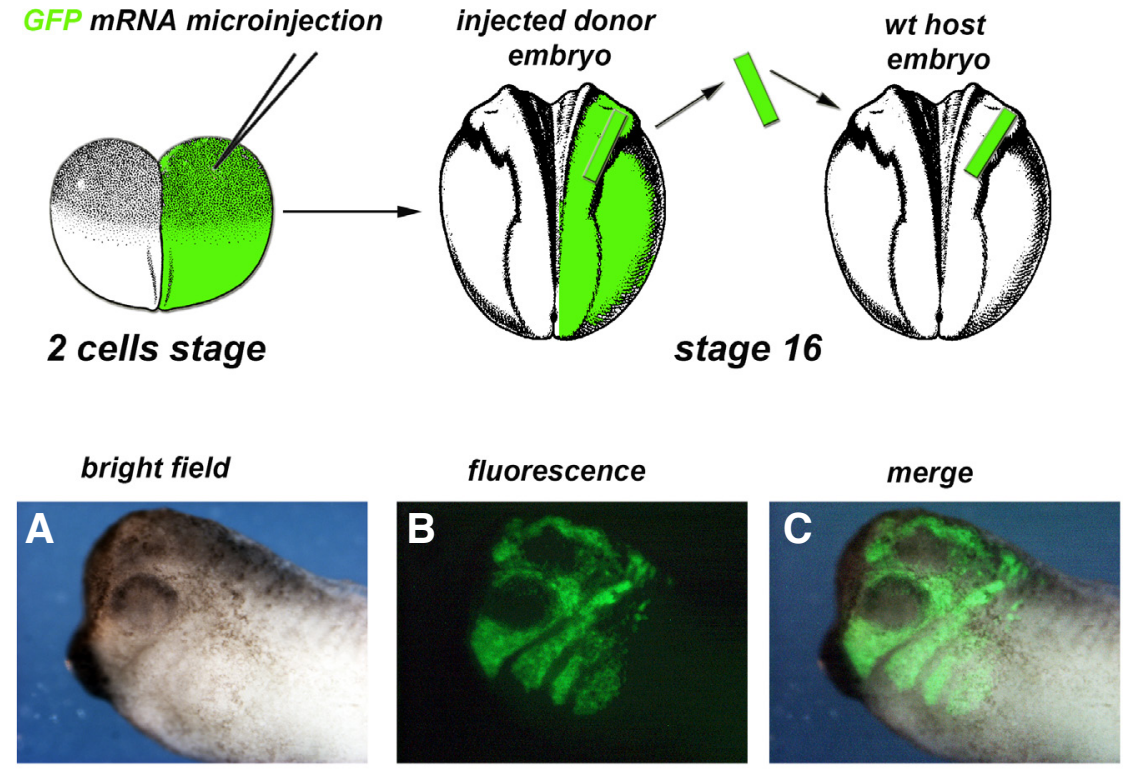

Fig. 2. Neural crest cell transplantation assay. Top: Scheme of the cranial NCCs transplant assay at neurula stage (st. 16). (A,B,C) Lateral views of an early tailbud (stage 28) transplanted embryo: (A) bright field; (B) GFP fluorescence in transplanted cranial NCCs; (C) merge.
Public databases harbor the nucleotide sequences of almost 2 million expressed sequences tag (EST) from both $X$. laevis and $X$. tropicalis (the diploid sister species of $X$. laevis, whose genome is nearly sequenced) and microarrays are available for both species, thus an impressive collection of genomic and transcriptomic tools is rapidly becoming available for this model system.

Xenopus as a tetrapod shares a long evolutionary history with mammals: they share similarities at the level of the genomes, in organ development, anatomy and physiology and therefore it represents an excellent model to predict human biology.

\section{5-HT and 5-HT2B receptor in Xenopus development}

In Xenopus embryos 5-HT is present as a maternal pool in the eggs and the main components of the serotonergic system are expressed during the earliest stages of embryonic development (Fukumoto et al., 2005; Nikishin et al., 2012).

In the CNS 5-HT is first produced by serotonergic neurons of the raphe nuclei at tailbud stages (van Mier et al., 1986). Serotonergic cells are found in

Xenopus is a genus of aquatic frogs, native to southern Africa, that are tolerant to starvation, diseases and other insults that make them very easy to keep in captivity. Thus Xenopus has become a very widely used model organism for a variety of biological and biomedical researches. In particular, Xenopus is one of the most popular systems used in the field of developmental biology since it offers experimental advantages over other widely used model systems such as mice. These advantages come from the large number, accessibility and large size of the eggs, which can be easily fertilized in vitro producing huge numbers of synchronized embryos that can be observed developing from the first cell division to a tadpole in about 36 hours (Fig. 1). The embryos can be easily manipulated, injected, grafted or labeled. In particular, researchers can easily manipulate gene functions in large numbers of embryos by using morpholino-modified antisense oligos and by mRNA mis-expression. This can be performed by injecting morpholinos or in vitro transcribed mRNAs into one cell of the two-cell stage embryos. This procedure provides a useful internal control, as the first cleavage results in gene down or up-regulation in only one side of the embryo (Fig. 1). In addition, the availability of a well-defined fate map of each blastomere allows addressing the microinjection in specific regions of the embryo so that a morpholino-mediated conditional knockdown approach can be easily obtained. This approach can overcome lethal effects and allows studying defects that appear in later stages of development. A homotipic transplant assay system has also been settled up in Xenopus embryos allowing detecting cell contribution to specific structures as well as the cell autonomous or non-autonomous contribution of specific gene activity in developmental processes (Borchers et al., 2000; Reisoli et al., 2010) (Fig. 2). Xenopus is also successfully used for chemical genetics and drug screen studies (Wheeler and Brändli, 2009). In particular, chemical genetics provides a complementary approach to loss or gain of function mutations in the study of complex biological processes. several other tissues or organs of the Xenopus larvae, such as the retina, the skin and the gut (Figs. $3 ; 4 \mathrm{~A}$ ). A specific population of neuroepithelial cells in Xenopus gills has also been shown to contain 5-HT (Saltys et al., 2006).

The cloning of the Xenopus 5-HT2B cDNA revealed that the predicted protein is conserved among vertebrates, thus substantiating the role of Xenopus as a model system (De Lucchini et al., 2003). Two alternative polyadenylation sites were found. The same situation was found in the puffer fish Tetraodon, so that a functional significance for the use of alternative polyadenylation sites, conserved in evolution, may be hypothesized (De Lucchini et al., 2001). The genomic organization of the 5-HT2B receptor in Xenopus has not been addressed. However, in other organisms such as Tetraodon and humans, splice variants and truncated forms of the protein have been described (De Lucchini et al., 2001; Deraet et al., 2004). It is interesting to note that in some instances mutations causing premature truncation of the protein product are related to human diseases such as fenfluramine-associated primary pulmonary hypertension (Blanpain et al., 2003) or with psychiatric diseases (Bevilacqua et al., 2010).

In Xenopus the 5-HT2B mRNA expression has been detected in the post-hatching stages in proliferating regions of the CNS and retina, in cranial NCCs and in periocular mesenchyme (POM) (De Lucchini et al., 2003; Reisoli et al., 2008; Reisoli et al., 2010).

Pharmacological treatments with the 5-HT2B antagonist ritanserin resulted in developmental defects strongly indicating that this receptor has a role in Xenopusembryogenesis. Morphological alterations included reduced pigmentation and heart defects with reduced heartbeats and pericardial edema. Similar heart defects have been found in ritanserin-treated mouse embryos (Choi et al., 1997). Ritanserin-treated Xenopus embryos also revealed ocular defects characterized by small and dorsalized eyes with a protruding lens, delay in the closure of the optic fissure (coloboma) and disorganized retinal cytoarchitecture (De Lucchini et al., 2005). 


\section{Role of 5-HT2B signaling in retinal layering and ocular morphogenesis}

The vertebrate retina is a powerful model to study how the nervous system is built up. Progenitor cells proliferate to generate six types of neurons and one type of glia, arranged into distinct layers. A number of molecules, including transcription factors and cell surface receptors, are involved in cell fate determination of retinal cell types (cf. Andreazzoli, 2009 for a review). In addition, both cell-intrinsic and -extrinsic cues must control the laminar organization of the retina. Recent evidence demonstrated that a wide range of neurotransmitters and their receptors are present during early stage of vertebrate retina development and it has been suggested that neurotransmitters may be numbered among the extracellular signals contributing to the retinal development. A precise coordination of retinal progenitor cell proliferation is essential for the formation of a functionally mature retina. Deregulated cell proliferation may in fact lead to dysplasia, retinal degeneration or retinoblastoma. There is now growing evidence that neurotransmitter systems modulate the proliferation and differentiation of retinal progenitor cells. The purinergic and muscarinic systems, for example, may take part in the control of retinoblasts proliferation while GABA, glutamate and dopamine appear to be involved in cell cycle exit and possibly in cell differentiation (for a review see Martins and Pearson, 2008). 5-HT was predicted to be among the important players, as it is both produced and accumulated in the developing retina (Figs. 3; 4A). Moreover, studies carried out in mammals and in Xenopus demonstrated that the retina receives serotonergic afferents directly from serotonergic neurons located in the dorsal raphe nuclei denoted as serotonergic retinopetal projections (Gastinger et al., 2006).

In Xenopus retina 5-HT accumulating amacrine cells are found starting from tailbud stage $35 / 36$, a time when retinal stratification is underway, but before the elaboration of either of the plexiform
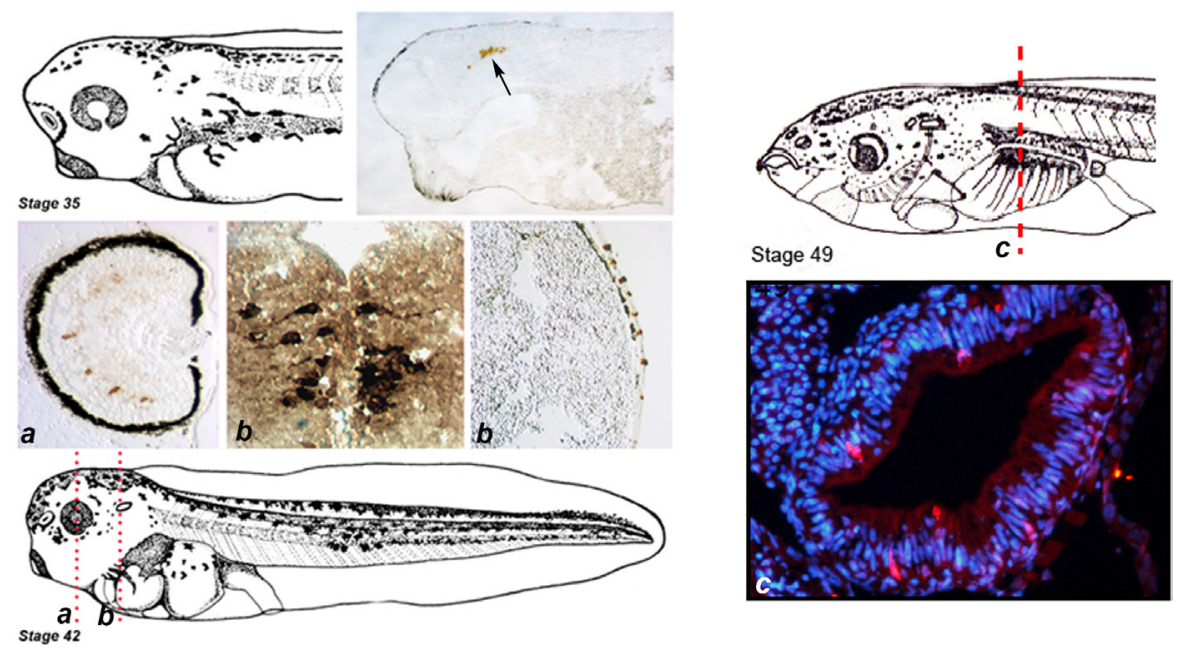

Fig. 3. Visualization of serotonergic cells during Xenopus embryogenesis. Distribution of serotonergic cells in Xenopus larvae, as detected in cryostat sections by immunostaining with an anti-serotonin antibody. Left panel, upper row: sagittal section of a late tailbud (stage 35) larva showing serotonin cells in the raphe nuclei (arrow); middle row, from left to right: serotonergic cells are found in the retina (amacrine cells), in the raphe nuclei, and in the skin of a late tailbud (stage 42) larva. Right panel: coronal section showing serotonin cells detected in the gut of a stage 49 tadpole (red fluorescence). Coronal planes are indicated as a, b, c. layers (Frederick et al., 1989; Huang and Moody, 1997). Different populations of 5 -HT-immunoreactive amacrine and bipolar cells are found in the inner nuclear layer (INL) and in the gaglion cell layer (GCL) (displaced amacrine cells), but only a subtype of amacrine cells actually synthesizes $5-\mathrm{HT}$. Interestingly, the total number of 5-HT-immunoreactive cells steadily increases through the early tadpole stages, peaks at stage 44 and then decreases, whereas the number of 5-HT-synthesizing cells continually increases with age (14-fold, from 57 to 774 in adult). This fluctuation is due to a transient population of amacrine cells that accumulate $5-\mathrm{HT}$ but do not synthesize it (Zhu and Straznicky, 1992; Huang and Moody, 1997). The changes in cell number parallel the changes in absolute amount of 5-HT measured in the retina at different developmental stages (Frederick et al., 1989). This may suggest that changes in 5-HT homeostasis at specific developmental periods influence retinal morphogenesis. Photoreceptor cells have also been reported to synthesize 5-HT, providing a supply of the substrate needed for the production of melatonin, in both mammals and amphibia (Zhu et al., 1992; Green et al., 1995).

Different 5-HT receptors are expressed in the retina of mammals including humans (Sharif and Senchyna, 2006). In Xenopus at least three 5-HT receptor mRNAs, coding for 5-HT1A, 5-HT2B and $5-H T 2 C$ respectively, are expressed in the larval retina (Marracci et al., 1997; De Lucchini et al., 2003). Pharmacological evidence, coupled with the 5-HT2B receptor spatio-temporal gene expression pattern, suggested that this receptor could be the candidate mediator of the 5-HT action on retinal development. The most prominent 5-HT2B mRNA expression in the retina was found in the tadpole ciliary marginal zone (CMZ), which is the source of retinal stem cells during the amphibian larval and adult life. 5-HT2B mRNA was also localized in differentiated retinal cells mainly in the INL and GCL (De Lucchini et al., 2003).

Loss of function experiments using morpholinos targeting the 5-HT2B mRNA resulted in loss of the characteristic retinal laminar cytoarchitecture (Fig. 4). These morphological defects reproduced those observed after ritanserin treatment. The altered retinal morphology was not due to deregulation of gene expression of specific cell differentiation markers, as markers for retinal cell layers are expressed in 5-HT2Bmorphants. Both ritanserin and 5-HT2B morpholino treatments increased the number of apoptotic cells in Xenopus retina (De Lucchini et al., 2005).

The upregulation of the 5-HT2B receptor activity did not affect retinoblast fate choice and terminal differentiation since all the main retinal cell subtypes were present in 5-HT overexpressing embryos, although they may be displaced outside their proper position and layer and rosette-like structures may form. Despite the severe alteration in layering, 5-HT2B up-regulated retinas did not show increase in apoptotic rate suggesting that $5-\mathrm{HT} 2 \mathrm{~B}$ receptor may function in modulating retinoblast proliferation and survival (Reisoli et al., 2008).

Further support to these findings came from in vitro studies showing that the $5-\mathrm{HT} 2 \mathrm{~B}$ overexpression was found per se sufficient to promote 
cell proliferation in a neuroblastoma cell line (Reisoli et al., 2008). These observations are in line with reports demonstrating that 5- $\mathrm{HT}$, via 5-HT2B receptor, is an important regulator of cardiac myocyte proliferation and survival during mouse development (Nebigil and Maroteaux, 2001; Nebigil et al., 2003).

The analysis of clones derived from lipofected retinoblasts constitutively expressing $5-\mathrm{HT} 2 \mathrm{~B}$ showed a significant increase in the percentage of ganglion cells. Ganglion cells are very sensitive to cell death regulation and are specifically targeted by survival factors: 5-HT may be counted among these factors (De Lucchini et al., 2005).

On the whole, the comparison between $5-H T 2 B$ gene loss and gain of function experiments points out that serotonin signaling via 5-HT2B receptor is essential for the frog mature retina functionality allowing the completion of the retinal layering process by supporting retinoblast proliferation and survival but it is not a determinant for specific retinoblasts differentiation.

Pharmacological and functional in vivo studies revealed another interesting aspect of the 5-HT2B function in ocular development. The altered orientation, position and conformation of the eye in the larval head cannot be directly explained by mechanisms involved in retinal histogenesis. Other ocular defects observed in 5-HT2B deregulated embryos are a shorter optic nerve and a failure of the choroid fissure closure or coloboma (Fig. 4). A detailed analysis of the 5-HT2B mRNA expression pattern revealed its presence in the POM, a population of mesenchymal cells derived from both the mesoderm and cranial NCCs that surrounds the developing eye (Reisoli et al., 2008). POM is known to provide multiple cell lineages necessary for normal ocular development as well as essential signals for the patterning of ocular primordia including the morphogenetic extension of the optic stalk, the anterior eye segment development and the optic fissure closure (Gage et al., 2005). Additional studies are required to unveil the role of $5-\mathrm{HT} 2 \mathrm{~B}$ signaling in POM development.

\section{5-HT2B signaling and craniofacial morphogenesis/jaw joint formation: implications in human birth defects}

The fact that 5-HT may play a role in mouse craniofacial morphogenesis was known from time, and malformations caused by exposure of cultured mouse embryos to selective 5-HT re-uptake inhibitors, such as fluoxetine (SSRI, Prozac) and 5-HT receptor antagonists were reported (Shuey et al., 1992; Moiseiwitsch, 2000). Craniofacial morphogenesis is a complex developmental process requiring multiple and coordinated embryological events. The visceral skeleton of all jawed vertebrate embryos is organized into a rostrocaudal bilateral series of pharyngeal arches that are colonized by cranial NCCs, migrating along precise pathways from the mid-hindbrain segments of the neural tube. The NCC components of the branchial arches give rise to different skeletal elements that undergo profound changes during evolution (SaukaSpengler and Bronner-Fraser, 2008). In addition, signals from the endoderm and the ectoderm, which overlie the branchial arches, are crucial for correct craniofacial development and in particular for the specification of the first branchial arch (reviewed in Minoux and Rijli, 2010). Defining the network that orchestrates such a complex series of events is critically important as developmental mistakes may occur, leading to NCC-related developmental defects, such as craniofacial abnormalities, which account for one-third of all congenital human birth defects.

$5-H T 2 B$ mRNA is present in the branchial arches of late tailbud Xenopus embryos, as well as in the branchial arches of the mouse embryo at E9 (Choi et al., 1997; Lauder et al., 2000; Reisoli et al., 2010). However, developmental craniofacial defects in 5-HT2B knockout mouse embryos have not been reported, probably because the most penetrating phenotype of $5-H T 2 B$ mutant mice leads to early embryonic death in utero (Nebigil et al., 2000). A possible role of the $5-\mathrm{HT} 2 \mathrm{~B}$ signaling in craniofacial morphogenesis was suspected due to the potent teratogenic activity of its antagonists in cultured mouse embryos (Choi et al., 1997; Bhasin et al., 2004). In spite of this evidence, the precise mechanisms of the 5-HT2B function in craniofacial morphogenesis awaited to be defined.

The first hint to a possible 5-HT2B role in the frog craniofacial morphogenesis came from overexpression experiments showing a craniofacial skeleton alteration. This phenotype was characterized by the formation of an ectopic cartilaginous element, by a reduction in the quadrate and subocular cartilages and by altered orbitohyoideus muscle connectivity. In 5-HT2B overexpressing embryos Xbap (also known as $N k x 3.2$ ), a gene codifing for a trascription
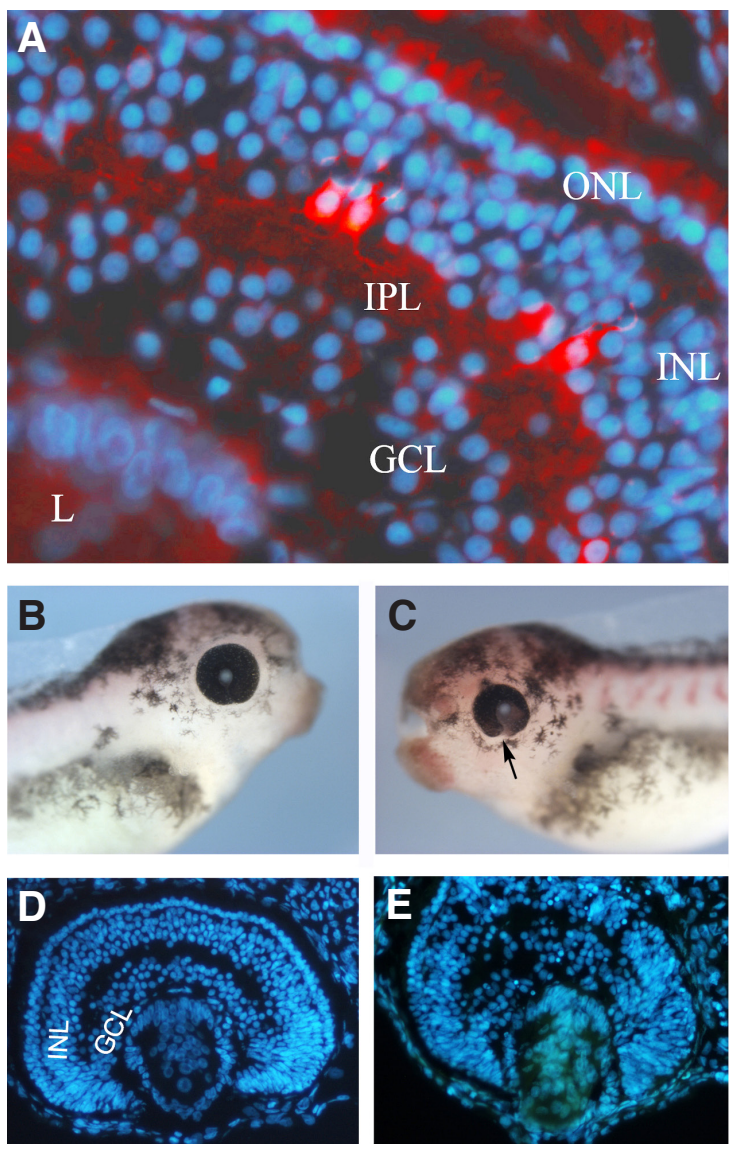

Fig. 4. Role of serotonergic signaling during eye development. (A) Serotonergic amacrine cells in Xenopus stage 42 retina (red immunostaining) (B-E) Effects of 5-HT2B morpholino injection on Xenopus eye development. Lateral (B,C) views of control and injected side of the same tadpole (st. 42). The arrow in (C) points to the optic fissure that fails to close ventrally. (D,E) Hoechst nuclear staining (blue) of cryostat eye cross-sections of control and morpholino-injected stage 42 tadpole: note the altered retinal layering in (E). ONL, outer nuclear layer; INL, inner nuclear layer; IPL, inner plexiform layer; GCL, ganglion cell layer; L, lens. 

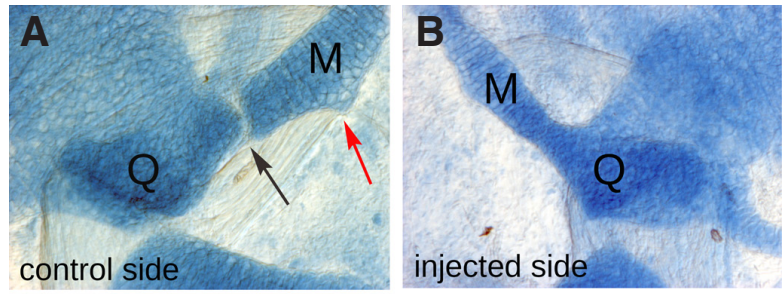

5-HT2B receptor and jaw joint formation
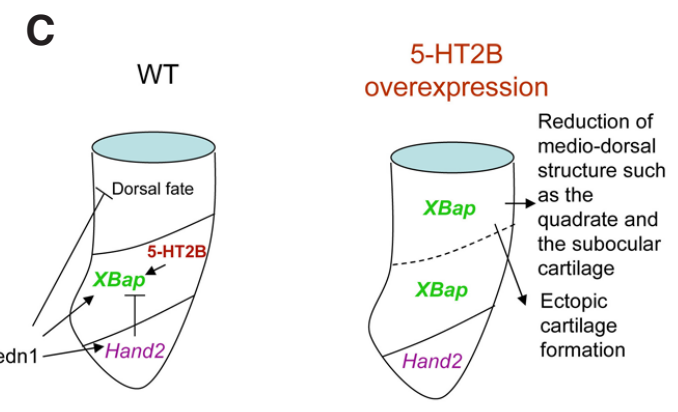

\section{$5-\mathrm{HT} 2 \mathrm{~B}$}

morphant

First branchial arch

Fig. 5. Role of serotonergic signaling in the first branchial arch development. $(A, B)$ Craniofacial skeletal alterations in 5-HT2B morphants (st. 49). Alcian blue staining of a flat mount embryo showing the jaw joint region of the control (A) and injected (B) side. The jaw joint (black arrow in the control side) is lacking in the injected side; note also the reduction of the quadrate (Q) and the absence of the ventral cartilaginous muscular process of the Meckel's cartilage, which is present in the control side (red arrow). $Q$, quadrate; M, Meckel's cartilage. (C) Scheme of the role of the $5 H T-2 B$ receptor signaling in patterning the dorso-ventral axis of the first branchial arch. The scheme is based on the experimental data reported in Reisoli et al., 2010. 5-HT2B receptor signaling is both sufficient and necessary to induce and maintain Xbap (Nkx2.2) gene expression in the medial region of first branchial arch giving rise to the jaw joint, possibly cooperating with endothelin receptor signaling.

factor expressed in the precursor cells of the jaw joint region, was ectopically expressed, resembling a mirror-image duplication of the wild-type Xbapexpression. As shown by homotipic trasplant assay, the 5-HT2B activity in NCCs was sufficient, in a cell-autonomous manner, to generate the ectopic cartilage. More importantly, 5HT2B activity was not only sufficient but also necessary to shape the first branchial arch skeletal elements. Knockdown of 5-HT2B expression in Xenopus embryos resulted in Xbap downregulation and in a fusion of a hypomorphic quadrate with the Meckel's cartilage into a single element, leading to the loss of the jaw joint (Fig. 5 A-B). The 5-HT2B signaling is therefore required to define and sustain the Xbap gene expression necessary for the jaw joint formation, which is one the major evolutionary novelties of vertebrates (Reisoli etal., 2010). Another signaling pathway known to be able to positively control Bapx 1 expression is endothelin 1 (Edn1) (Walker et al., 2007). Since both endothelin and 5-HT2B signaling act through the PLC beta 3 effector (Raymond et al., 2001), they could cooperate in modulating Xbap expression and reinforcing the PLC pathway in cranial NCCs during the first arch patterning (Reisoli et al., 2010) (Fig. 5C). As the regulatory network involved in the specific expression of Bapx 1 in vertebrates is conserved (Newman et al., 1997; Miller et al., 2003; Tucker et al., 2004), it may be hypothesized that 5-HT2B signaling controls Bapx1 expression in mammalian embryos as well. This aspect, to be verified and further explored, could be of interest particularly in the light of the possible involvement of BAPX1 in human birth defects, such as the oculo-articular-vertebral spectrum (OAVS), which exhibits alterations in the first and second branchial arch derivatives (Fischer et al., 2006).

In conclusion the data obtained in the experimental model Xenopus revealed that the 5-HT2B signaling can be included into the complex interactive network of extrinsic factors that regulates craniofacial skeleton development in vertebrates.

\section{Concluding remarks}

Work in a suitable vertebrate model system such as Xenopus embryos revealed novel roles of the 5-HT/5HT2B signaling in eye and craniofacial morphogenesis. These findings are not only relevant in terms of evolutionary biology but may have consequence in our understanding of congenital defects, including human birth abnormalities.

The role of 5-HT2B receptors in ocular and facial morphogenesis is consistent with their expression in cranial NCCs, a transient population of migratory embryonic multipotent cells that arises from neural ectoderm and populates the pharyngeal arches. Disruption of cranial NCCs development lead to human congenital craniofacial and ocular defects that are included among the so called "neurocristopathies". Although these disorders are generally associated to genetic abnormalities, they can also be induced by prenatal exposure to teratogens. SSRIs represent a class of commonly used antidepressants in pregnant and lactating women and several epidemiological investigations reportlong-lasting molecular, physiological and behavioral changes in offspring prenatally exposed to SSRIs such as persistent pulmonary hypertension, cardiac defects and spontaneous abortion (Oberlander et al., 2009; Tuccori et al., 2009; Bellissima et al., 2012). An association between congenital heart defects and the use of SSRIs in pregnancy has been demonstrated (Sadler, 2011) and these findings are in line with animal model studies showing a key role of 5-HT2B receptor signaling in heart development (Gaspar et al., 2003). Interestingly, recent investigations demonstrated that $5-\mathrm{HT} 2 \mathrm{~B}$ is required for serotonin selective antidepressant actions (Diaz et al., 2012) and in astrocytes fluoxetin and paroxetine (SSRIs) seem to act as subtype-specific agonists for 5-HT2B receptors (Zhang etal., 2010). Recently, the occurrence of OAVS, a syndrome characterized by abnormal development of facial structures derived from the first and second branchial arches, has been reported in an infant born to a woman with a history of prenatal fluoxetine treatment throughout her pregnancy, suggesting an involvement of 5-HT signaling also in human craniofacial morphogenesis (Farra et al., 2010). Cardiovascular malformations and facial dysmorphism have been reported in two twins born to a woman who used paroxetine (SSRI) during pregnancy (Marsella et al., 2010). A worldwide prospective analysis revealed that the incidence of mood and anxiety disorders is destined to progressively grow in the population so that a more extensive prescription of the SSRIs is expected to occur. This led to consecutive alerts by the U.S. Food and Drug Administration in 
2005 and 2006, stating that the use of SSRIs in pregnancy was associated with increased birth defects (Chambers et al., 2006, Wogelius et al., 2006). Prenatal exposure to SSRIs also impacts fetal brain development that may have long-term mental health implications (Hanley et al., 2013). The mode of action of SSRIs suggests the involvement of complicated downstream mechanisms, including long-term changes in gene expression and neuroplasticity. Experimental studies in rodents have in fact shown that administration of SSRIs during a key developmental window creates changes in brain circuitry and maladaptive behavior, such as increased anxiety in adulthood (Ansorge et al., 2008). On the whole, these discoveries have significant implications for the prescription of antidepressants to pregnant women and should stimulate further animal models and human research efforts.

\section{Acknowledgements}

This work was financed by grants from the Scuola Normale Superiore of Pisa (Italy), project "Role of the serotonergic receptor 2B in ocular and craniofacial morphogenesis: implications in human congenital malformations and in the possible effects of SSRI in human fetus development" (2011) and from MIUR, Rome, Italy, PRIN 2008, project "Molecular and evolutionary aspects of the neuronal differentiation".

\section{References}

ANDREAZZOLI M (2009). Molecular regulation of vertebrate retina cell fate. Birth Defects Research (Part C) 87: 284-295.

ANSORGE MS, MORELLI E, GINGRICH JA (2008). Inhibition of serotonin but not norepinephrine transport during development produces delayed, persistent perturbations of emotional behaviors in mice. J Neurosci 28: 199-207.

BERGER M, GRAY JA, ROTH BL (2009). The expanded biology of serotonin. Annu Rev Med 60: 355-366.

BELLISSIMA V, VERVERS TFF, VISSER GHA, GAZZOLO D (2012). Selective serotonin reuptake inhibitors in pregnancy. Curr Med Chem 19: 4554-4561

BERTON O, NESTLEREJ (2006). New approaches to antidepressant drug discovery: beyond monoamines. Nat Rev Neurosci 7: 137-151.

BEVILACQUA L, DOLY S, KAPRIO J, YUAN Q, TIKKANEN R, PAUNIO T, ZHOU Z, WEDENOJA J, MAROTEAUX L, DIAZ S, BELMER A, HODGKINSON CA, DELL'OSSO L, SUVISAARI J, COCCARO E, ROSE RJ, PELTONEN L, VIRKKUNEN M, GOLDMAN D (2010). A population-specific HTR2B stop codon predisposes to severe impulsivity. Nature468: 1061-6. Erratum in: Nature2011, 470:424.

BEYER T, DANILCHICK M, THUMBERGER T, VICK P, TISLER M, SCHNEIDER I, BOGUSCH S, ANDRE P, ULMER B, WALENTEK P, NIESLER B, BLUM M, SCHWEICKERTA(2012). Serotonin signaling is required for Wnt-dependent GRP specification and leftward flow in Xenopus. Curr Biol 22: 33-39.

BHASIN N, LA MANTIA AS, LAUDER JM (2004). Opposing regulation of cell proliferation by retinoic acid and the serotonin $2 \mathrm{~B}$ receptor in the mouse frontonasal mass. Anat Embryol 208: 135-143.

BLANPAIN C, LE POUL E, PARMA J, KNOOP C, DETHEUX M, PARMENTIER M, VASSART G, ABRAMOWICZ MJ (2003). Serotonin 5-HT(2B) receptor loss of function mutation in a patient with fenfluramine-associated primary pulmonary hypertension. Cardiovasc Res 60: 518-28.

BONNIN A, TORII M, WANG L, RAKIC P, LEVITTP (2007). Serotonin modulates the response of embryonic thalamocortical axons to netrin-1. NatNeurosci10:588-597.

BONNIN A, GOEDEN N, CHEN K, WILSON ML, KING J, SHIH JC, BLAKELY RD, DENERIS ES, LEVITT P (2011). A transient placental source of serotonin for the fetal forebrain. Nature 472: 347-350.

BORCHERS A, EPPERLEIN HH, WEDLICH D (2000). An assay system to study migratory behavior of cranial neural crest cells in Xenopus. Dev Genes Evol 210: 217-222

BUZNIKOV GA (2007). Preneural transmitters as regulators of embryogenesis. Current state of the problem. Russ J. Dev Biol 38: 213-220.

CASES O, VITALIS T, SEIF I, DE MAEYER E, SOTELO C, GASPAR P (1996). Lack of barrels in the somatosensory cortex of monoamine oxidase A-deficient mice: role of a serotonin excess during the critical period. Neuron 16: 297-307.

CHAMBERS C D, HERNANDEZ-DIAZS, VAN MARTER LJ, WERLER M M, LOUIKC JONES KL, MITCHELLAA(2006). Selective serotonin-reuptake inhibitors and risk of persistent pulmonary hypertension of the newborn. N Engl J Med354:579-587.

CHOIDS, WARD SJ, MESSADDEQ N, LAUNAY JM, MAROTEAUX L (1997). 5-HT2B receptor-mediated serotonin morphogenetic functions in mouse cranial neural crest and myocardiac cells. Development 124: 1745-1755

CÔTÉ F, FLIGNY C, BAYARD E, LAUNAY JM, GERSHON MD, MALLETJ. VODJDANI $\mathrm{G}$ (2007). Maternal serotonin is crucial for murine embryonic development. Proc Natl Acad Sci USA 104: 329-334.

DE LUCCHINI S, MARRACCI S, NARDI I (2001). The serotonin 5-HT2B receptor from the puffer fish Tetraodon fluviatilis: cDNA cloning, genomic organization and alternatively spliced variants. Brain Res Mol Brain Res 97: 89-93.

DE LUCCHINI S, ORI M, NARDINI M, MARRACCI S, NARDI I (2003). Expression of $5-\mathrm{HT} 2 \mathrm{~B}$ and $5-\mathrm{HT} 2 \mathrm{C}$ receptor genes is associated with proliferative regions of Xenopus developing brain and eye. Brain Res. Mol. Brain Res 115: 196-201.

DE LUCCHINI S, ORI M, CREMISI F, NARDINI M, NARDI I (2005). 5-HT2B mediated serotonin signaling is required for eye morphogenesis in Xenopus. Mol Cell Neurosci 29: 299-312.

DERAET M, MANIVET P, JANOSHAZI A, CALLEBERT J, GUENTHER S, DROUET L, LAUNAY JM, MAROTEAUX L (2005). The natural mutation encoding a $C$ terminus truncated 5 -HT2B receptor is a gain of proliferative functions. Molec. Pharmacol. 67: 983-991.

DIAZ S L, S DOLY S, N NARBOUX-NÊME N, S FERNÁNDEZ S, P MAZOT P, S M BANAS SM, K BOUTOURLINSKY K, I MOUTKINE I, A BELMER A, A ROUMIER A, AND L MAROTEAUX L (2012). 5-HT2B receptors are required for serotoninselective antidepressant actions. Mol Psychiatry 17: 154-163.

FARRA C, YUNIS K, MIKATI M, YAZBECK N, MAJDALANI M, AWWAD J (2010) Goldenhar syndrome associated with prenatal maternal Fluoxetine ingestion Cause or coincidence? Birth Defects Res A Clin Mol Teratol 88: 582-5.

FISCHER S, LÜDECKE HJ, WIECZOREK D, BÖHRINGER S, GILLESSENKAESBACH G, HORSTHEMKE B (2006). Histone acetylation dependent allelic expression imbalance of BAPX1 in patients with the oculo-auriculo-vertebral spectrum. Hum Mol Genet 15: 581-587.

FREDERICK JM, RAYBORN ME, HOLLYFIELD JG (1989). Serotoninergic neurons in the retina of Xenopus laevis: selective staining, identification, development, and content. J. Comp. Neurol. 281: 516-531.

FUKUMOTO T, KEMA IP, LEVIN M (2005). Serotonin signaling is a very early step in patterning of the left-right axis in chick and frog embryos. Curr Biol 15: 794-803

GAGE PJ, RHOADES W, PRUCKA SK, HJALT T (2005). Fate maps of neural crest and mesoderm in the mammalian eye. Invest Ophthalmol Vis Sci 46: 4200-4208.

GASPAR P, CASES O, MAROTEAUX L (2003). The developmental role of serotonin news from mouse molecular genetics. Nat Rev Neurosci 4: 1002-1012.

GASTINGER MJ, TIAN N, HORVATH T, MARSHAK DW (2006). Retinopetal axons in mammals: emphasis on histamine and serotonin. Curr Eye Res 31: 655-667.

GREEN CB, CAHILL GM, BESHARSE JC (1995). Tryptophan hydroxylase is expressed by photoreceptors in Xenopus laevis retina. Vis. Neurosci. 12: 663-670

HANLEY GE, BRAIN U, OBERLANDER TF (2013). Infant developmental outcomes following prenatal exposure to antidepressants, and maternal depressed mood and positive affect. Early Hum Dev, Feb 2. pii: S0378-3782(13)00015-7. doi: 10.1016/j.earlhumdev.2012.12.012. [Epub ahead of print]

HUANG S, MOODY SA (1997). Three types of serotonin-containing amacrine cells in tadpole retina have distinct clonal origins. J Comp Neurol 387: 42-52

LAUDER JM (1993). Neurotransmitters as growth regulatory signals: role of receptors and second messengers. Trends Neurosci 16: 233-240.

LAUDER JM, ZIMMERMAN EF 1988. Sites of serotonin uptake in epithelia of the developing mouse palate, oral cavity, and face: possible role in morphogenesis. J Craniofac Genet Dev Biol 8: 265-76.

LAUDER J M, WILKIE MB, WU C, SINGHS (2000). Expression of 5-HT(2A), 5-HT(2B) and 5-HT(2C) receptors in the mouse embryo. Int J Dev Neurosci 18: 653-662.

LAUNAY JM, SCHNEIDER B, LORIC S, DA PRADA M, KELLERMAN O (2006) Serotonin transport and serotonin transporter-mediated antidepressant recognition are controlled by 5 -HT2B receptor signaling in serotonergic neuronal cells. FASEB J 20: 1843-54. 
LEVIN M, BUZNIKOV GA, LAUDER JM (2006). Of minds and embryos: left-right asymmetry and the serotonergic controls of pre-neural morphogenesis. Dev Neurosci 28: 171-185.

MARRACCI S, CINI D, NARDI I (1997). Cloning and developmental expression of 5-HT1A receptor gene in Xenopus laevis. Brain Res Mol Brain Res 47: 67-77.

MARSELLA M, UBALDINI E, SOLINAS A, GUERRINI P (2010). Prenatal exposure to serotonin reuptake inhibitors: a case report. Ital. J. Pediatrics 36: 27-29.

MARTINS RA, PEARSON RA (2008). Control of cell proliferation by neurotransmitters in the developing vertebrate retina. Brain Res 1192: 37-60.

MIGLIARINI S, PACINI G, PELOSI B, LUNARDI G, PASQUALETTI M (2012). Lack of brain serotonin affects postnatal development and serotonergic neuronal circuitry formation. Molec. Psychiatry Sep 25, 1-13 doi: 10.1038/mp.2012.128. [Epub ahead of print]

MILLER CT, YELON D, STAINIER DY, KIMMEL CB (2003). Two endothelin 1 effectors, hand2 and bapx1, pattern ventral pharyngeal cartilage and the jaw joint. Development 130: 1353-1365.

MINOUX M, RIJLI FM (2010). Molecular mechanisms of cranial neural crest cell migration and patterning in craniofacial development. Development 137:2605-21.

MOISEIWITSCH JR (2000). The role of serotonin and neurotransmitters during craniofacial development. Crit Rev Oral Biol Med 11: 230-239.

NARBOUX-NÊME N, PAVONE LM, AVALLONE L, ZHUANG X, GASPAR P (2008). Serotonin transporter transgenic (SERTcre) mouse line reveals developmental targets of serotonin specific reuptake inhibitors (SSRIs). Neuropharmacology 55: 994-1005.

NEBIGIL CG, CHOI DS, DIERICH A, HICKEL P, LE MEUR M, MESSADDEQ N, LAUNAY JM, MAROTEAUX L (2000). Serotonin 2B receptor is required for heart development. Proc Natl Acad Sci USA 97: 9508-9513.

NEBIGIL CG, MAROTEAUX L (2001). A novel role for serotonin in heart. Trends Cardiovasc Med 11: 329-335.

NEBIGIL CG, ETIENNE N, MESSADDEQ N, MAROTEAUX L (2003). Serotonin is a novel survival factor of cardiomyocytes: mitochondria as a target of 5-HT2B receptor signaling. FASEB $J$ 17: 1373- 1375

NEWMAN C S, GROW MW, CLEAVER O, CHIA F, KRIEG P (1997). Xbap, a vertebrate gene related to bagpipe, is expressed in developing craniofacial structures and in anterior gut muscle. Dev Biol 181: 223-233.

NIKISHIN DA, KREMNYOV SV, KONDUKTOROVA VV, SHMUKLER YB (2012). Expression of serotonergic system components during early Xenopus embryogenesis. Int J Dev Biol 56: 385-91.

OBERLANDERTF, GINGRICH JA, ANSORGEMS (2009). Sustained neurobehavioral effects of exposure to SSRI antidepressants during development: molecular to clinical evidence. Clin Pharmacol Ther 86: 672-677

PERSICO AM, MENGUAL E, MOESSNER R, HALL FS, REVAY RS, SORA I, ARELLANO J, DEFELIPE J, GIMENEZ-AMAYA JM, CONCIATORI M, MARINO R, BALDI A, CABIB S, PASCUCCI T, UHL GR, MURPHY DL, LESCH KP, KELLER $F$ (2001). Barrel pattern formation requires serotonin uptake by thalamocortical afferents, and not vesicular monoamine release. J Neurosci 21: 6862-6873.

RAYMOND JR, MUKHIN YV, GELASCO A, TURNER J, COLLINSWORTH G, GETTYS TW, GREWAL JS, GARNOVSKAYA MN (2001). Multiplicity of mechanisms of serotonin receptor signal transduction. Pharmacol Ther 92: 179-212.

REISOLI E, DE LUCCHINI S, ANELLI, BIAGIONI S, NARDI I., ORI M (2008). Overexpression of 5-HT2B receptor results in retinal dysplasia and defective ocular morphogenesis in Xenopus embryos. Brain Res 9: 32-39
REISOLI E, DE LUCCHINI S, NARDI I., ORI M (2010). Serotonin 2B receptor signaling is required for craniofacial morphogenesis and jaw joint formation in Xenopus Development 137: 2927-2937.

SADLERTW (2011). Selective serotonin reuptake inhibitors (SSRIs) and heart defects: potential mechanisms for the observed associations. Reprod Toxicol 32: 484-9.

SALTYS HA, JONZ MG, NURSE CA (2006). Comparative study of gill neuroepithelial cells and their innervation in teleosts and Xenopus tadpoles. Cell Tissue Res 323: 1-10.

SAUKA-SPENGLER T, BRONNER-FRASER M (2008). A gene regulatory network orchestrates neural crest formation. Nat Rev Mol Cell Biol 9: 557-568.

SHAFER WR (1999). How do antidepressants work? Prospects for genetic analysis of drug mechanisms. Cell 98: 551-554

SHARIF NA, SENCHYNA M (2006). Serotonin receptor subtype mRNA expression in human ocular tissues, determined by RT-PCR. Mol Vis 12: 1040-7.

SHUEY DL, SADLER TW, LAUDER JM (1992). Serotonin as a regulator of craniofacial morphogenesis: site specific malformations following exposure to serotonin uptake inhibitors. Teratology 46: 367-378.

TSAPAKIS EM, GAMIE Z, TRAN GT, ADSHEAD S, LAMPARD A, MANTALARIS A, TSIRIDIS E (2012). The adverse skeletal effects of selective serotonin reuptake inhibitors. Eur. Psychiatry 27: 156-169

TUCCORI M, TESTI A, ANTONIOLI L, FORNAI M, MONTAGNANI S, GHISU N, COLUCCI R, CORONA T, BLANDIZZI C, DEL TACCAM (2009). Safety concerns associated with the use of serotonin reuptake inhibitors and other serotonergic/ noradrenergic antidepressants during pregnancy: a review. Clin Ther31:1426-53.

TUCKER A S, WATSON RP, LETTICE LA, YAMADA G, HILL RE (2004). Bapx1 regulates patterning in the middle ear: altered regulatory role in the transition from the proximal jaw during vertebrate evolution. Development 131: 1235-1245.

VAN MIER P, JOOSTEN HW, VAN RHEDEN R, TEN DONKELAAR HJ (1986). The development of serotonergic raphespinal projections in Xenopus laevis. Int $J$ Dev Neurosci 4: 465-75.

VANDENBERG LN, LEMIRE JM, LEVIN M (2013). Serotonin has early, cilia-independent roles in Xenopus left-right patterning. Disease Mod. Mech. 6: 261-268

WALKER MB, MILLER CT, SWARTZ ME, EBERHART JK, KIMMEL CB (2007). Phospholipase $C$, beta 3 is required for Endothelin1 regulation of pharyngeal arch patterning in zebrafish. Dev Biol 304: 194-207.

WHEELER GN, BRÄNDLI AW (2009). Simple vertebrate models for chemical genetics and drug discovery screens: lessons from zebrafish and Xenopus. Dev Dyn 238: 1287-308.

WHITAKER-AZMITIA PM 2001. Serotonin and brain development: role in human developmental diseases. Brain Res Bull 56: 479-485.

WOGELIUSPM, NORGAARDM, GISLUML, PEDERSENE, MUNK PB, MORTENSEN PB, LIPWORTH L, SØRENSEN HT (2006). Maternal use of selective serotonin reuptake inhibitors and risk of congenital malformations. Epidemiology 17: 701-704.

ZHANG S, LI B, LOVATT D, XU J, SONG D, GOLDMAN SA, NEDERGAARD M, HERTZ L, PENG L (2010). 5-HT2B receptors are expressed on astrocytes from brain and in culture and are a chronic target for all five conventional 'serotoninspecific reuptake inhibitors'. Neuron Glia Biol 6: 113-125.

ZHUB, STRAZNICKYC (1992). Large serotonin-like immunoreactive amacrine cells in the retina of developing Xenopus laevis. Brain Res., Dev. Brain Res. 69: 109-116.

ZHU B, GÁBRIEL R, STRAZNICKY C (1992). Serotonin synthesis and accumulation by neurons of the anuran retina. Vis Neurosci 9: 377-388. 


\section{Further Related Reading, published previously in the Int. J. Dev. Biol.}

Molecular signaling at the fusion stage of the mouse mandibular arch: involvement of insulin-like growth factor family. Kazuya Fujita, Yuji Taya, Yoshihito Shimazu, Takaaki Aoba and Yuuichi Soeno Int. J. Dev. Biol. (2013) 57: 399 - 406.

Expression of serotonergic system components during early Xenopus embryogenesis Denis A. Nikishin, Stanislav V. Kremnyov, Victoria V. Konduktorova and Yuri B. Shmukler Int. J. Dev. Biol. (2012) 56: 385-391 http://dx.doi.org/10.1387/ijdb.113475dn

Early neural cell death: numbers and cues from the developing neuroretina Ana I. Valenciano, Patricia Boya and Enrique J. de la Rosa

Int. J. Dev. Biol. (2009) 53: 1515-1528

http://dx.doi.org/10.1387/ijdb.072446av

Identification and gene expression of versican during early development of Xenopus.

Paola Casini, Michela Ori, Angela Avenoso, Angela D'Ascola, Paola Traina, Walter Mattina, Roberto Perris, Giuseppe M. Campo, Alberto Calatroni, Irma Nardi, Salvatore Campo.

Int. J. Dev. Biol. (2008) 52: 993 - 918.

The retinoic acid metabolising gene, CYP26B1, patterns the cartilaginous cranial neural crest in zebrafish.

Susan Reijntjes, Adam Rodaway, Malcolm Maden

Int. J. Dev. Biol. (2007) 51: 351 - 360

Effects of growth factors on the differentiation of neural crest cells and neural crest cell-derivatives

B K Hall and S Ekanayake

Int. J. Dev. Biol. (1991) 35: 367-387

http://dx.doi.org/10.1387/ijdb. 1801864

Fate of cranial neural crest cells during craniofacial development in endothelin-A receptor-deficient mice

Abe M, Ruest LB, Clouthier DE.

Int J Dev Biol. 51: 97-105.

Retinal ganglion cells: dying to survive

Guerin MB, McKernan DP, O’Brien CJ, Cotter TG.

Int J Dev Biol. 50: 665-674.

5 yr ISI Impact Factor $(2011)=2.959$
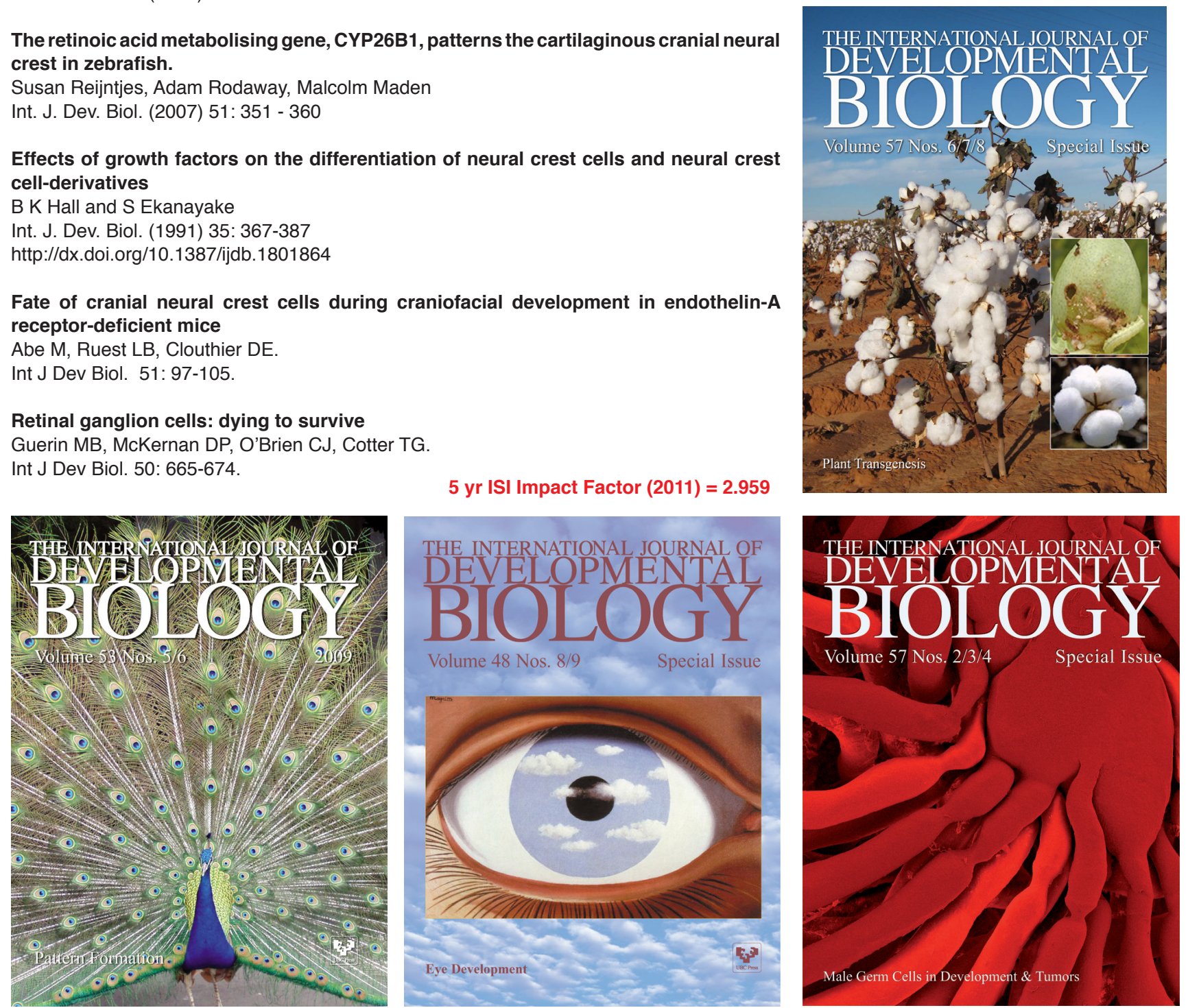